\title{
Microtecnologías para diagnósticos médicos más precisos y económicos
}

\author{
La empresa Bioarray, asentada en el Parque Científico, innova en técnicas \\ no-invasivas más efectivas y seguras para la detección de mutaciones genéticas
}

\section{Pátima Navarro-Maillo}

La empresa ilicitana Bioarray, asentada en el Parque Cientíico Empresarial de la UMH desde 2009, ha lanzado recientemente dos servicios para el diagnóstico génico que podrían revolucionar las técnicas de citogenética utilizadas hasta ahora, además de mejorar y agilizar el estudio del genoma humano, algo que podría ayudar a ajustar las terapias frente a enfermedades originadas por cambios en el ADN. Bioarray se integra también en la Plataforma de Investigación en Piel, una iniciativa en la que la UMH participa a través del Instituto de Biología Molecular y Celular.

La empresa de base tecnológica, Bioarray, se ha especializado en el análisis genético mediante microarrays de ADN, unas micromatrices que sirven de soporte para miles de genes. Los microarrays son capaces de explorar con una sola prueba el genoma completo, de modo que se reduce la incertidumbre del clínico, costes, tiempo y molestias para el paciente. "Con la citogenética clásica la tasa de diagnóstico está en torno al $7 \%-8 \%$, mientras que con los microarrays aumenta hasta un $18 \%-20 \%$ ", asegura Andrés Antón, gerente de la empresa. Un avance significativo de los microarrays es que permiten un "screening" de alto rendimiento para el diagnóstico del retraso mental.

\section{Técnicas pioneras}

El nuevo análisis de cribado prenatal no invasivo implantado por Bioarray, una técnica pionera en España, se presenta como una alternativa a la amniocentesis para aquellos casos en que, tras el cribado del primer trimestre, la embarazada sufre un riesgo leve, o cuando exista ansiedad materna. A partir de una muestra de sangre de la mujer embarazada, esta técnica asigna una estimación del riesgo fetal de padecer síndrome de Down, síndrome de Patau o síndrome de Edwards, alteraciones más frecuentes que se producen por una copia extra de cromosomas 21, 13 y 18 respectivamente. Así muchas embarazadas pueden evitar no sólo la incomodidad de la amniocentesis (implica la inserción de una aguja larga en el útero), sino también el riesgo derivado de aborto (próximo al 1\%).

\section{El diagnóstico de patologías mediante microarrays reduce costes, tiempos, riesgos y molestias a los pacientes}

Por otro lado, Bioarray también ha sumado a sus servicios una nueva tecnología que se conoce como secuenciación masiva, que refleja la distribución y composición de las cadenas de ADN. "Esta tecnología permite diagnosticar con una única prueba una o varias patologías derivadas de mutaciones genéticas, incluido el retraso mental, además de permitir otros experimentos para investigación", afirma Antón.

Más allá del área de negocio orientada a salud humana, Bioarray asesora a investigadores e instituciones de todo el territorio nacional. Una de las entidades con las que trabaja Bioarray es la Plataforma de Investigación en Piel, una iniciativa público-privada lanzada en 2010 por el catedrático de la UMH, Antonio Ferrer Montiel, en la que participa la universidad a través del Instituto de Biología Molecular y Celular (IBMC). Bioarray creó un microarray que centraba el análisis en genes relacionados con la epidermis.

Según David Vicente, responsable de Internacionalización, Bioarray ofrecerá sus servicios para el diagnóstico genético y de apoyo a la investigación en Latinoamérica y Europa. Sin embargo, Bioarray también debe darse a conocer entre los investigadores: "Deben saber que en el Parque Científico hay una empresa que ofrece servicios con tecnologías de alto rendimiento. Esta contratación de expertos reduce gastos, tiempo y facilita el trabajo a los grupos de investigación", apunta Antón. De hecho, según el gerente, la supervivencia de la investigación en un futuro próximo pasa inevitablemente por la unión de los profesionales. Una llamada a la cooperación entre la universidad, la investigación y la empresa que sustituya los esfuerzos individuales por una máxima suprema que recuerde que sólo la unión nos hará fuertes.

+ en umhsapiens.com

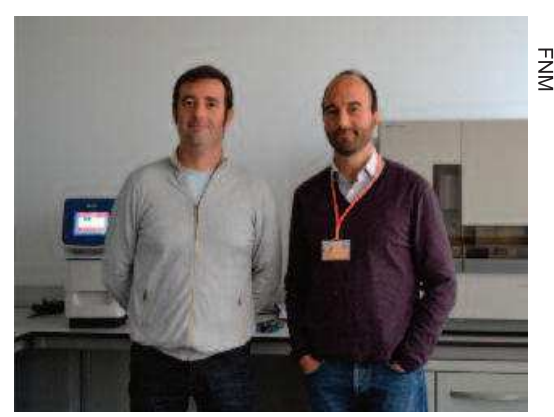

Andrés Antón y David Vicente, miembros de Bioarray 